Eixo Temático: Processos de Ensino-Aprendizagem

\title{
ET-06-010
}

\section{A (RE)CONSTRUÇÃO DOS CONCEITOS DE PRESERVAÇÃO E CONSERVAÇÃO AMBIENTAL A PARTIR DA RELAÇÃO ENTRE O CONHECIMENTO PRÉVIO E O CÍRCULO HERMENÊUTICO-DIALÉTICO}

Manoel Lucas Bezerra de Lima르, Jailson Rodrigues de Oliveira ${ }^{1}$, Ramon César Santos de Oliveira$^{1}$, Ricardo Ferreira das Neves ${ }^{2}$

\author{
${ }^{1}$ Graduandos em Licenciatura em Ciências Biológicas UFPE/CAV- E-mail: \\ manoel.lucas88@gmail.com. \\ 2Professor do Núcleo de Ciências Biológicas UFPE/CAV
}

http://dx.doi.org/10.21472/congrebio2016.et-06-010

\section{RESUMO}

A pesquisa objetivou analisar as concepções estudantes do Ensino Médio sobre os conceitos de preservação e conservação ambiental. Esses conceitos muitas vezes são tratados como sinônimos por apresentarem discussões relacionadas ao Meio Ambiente. Contudo, os sentidos empregados são bastante diferentes e quando não abordados corretamente pode vir a gerar obstáculos na aprendizagem dos estudantes e ainda contribuir numa interpretação errônea numa aplicação divergente do conhecimento científico. Nesse sentido, o uso de métodos diferenciados podem vir a colaborar significativamente em sua compreensão, de forma a (re)construir novas perspectivas aos sujeitos e consequentemente, novas mudanças de suas posturas com relação ao ambiente. A partir da relação entre o conhecimento prévio subsidiado pela técnica do Círculo Hermenêutico-Dialético (CHD) foram captadas as concepções de um grupo de estudantes sobre os conceitos de preservação e conservação ambiental. Inicialmente, os alunos apresentavam dificuldades para distinguir os conceitos, que após o processo de intervenção houve significativa revisão das ideias pelo grupo, com considerações mais elaboradas e próximas do conhecimento científico. A valorização dos conhecimentos prévios elencados ao CHD foi de extrema importância para o processo de ensino-aprendizagem, cuja sinergia proporcionou novas perspectivas aos estudantes em relação aos conceitos e sobre o ambiente.

Palavras-chave: Preservação e Conservação; Teoria da aprendizagem significativa, Círculo hemenêutico-dialético.

\section{INTRODUÇÃO}

A preocupação com o meio ambiente representa um tema bastante discutido, pois a utilização dos recursos naturais sem controle gera desequilíbrios a todos os ecossistemas. Na busca por mudanças, é necessário tratar da utilização consciente dos recursos naturais, cujas discussões devem perpassar âmbitos da área ambiental e permearem também a sala de aula, permitindo que os estudantes possam refletir sobre suas práticas e serem multiplicadores de informações (FREITAS, 2004).

Os Parâmetros Curriculares Nacionais (PCN) ressaltam a importância das discussões aos sujeitos sobre a preservação e a conservação ambiental, visando reflexões acerca da manutenção do equilíbrio ecológico (BRASIL, 2000). Esses conceitos muitas vezes são tratados como sinônimos por apresentarem discussões relacionadas ao Meio Ambiente, mas os sentidos empregados são bastante diferentes e quando não abordados corretamente pode vir a gerar 
obstáculos na aprendizagem dos estudantes e contribuir numa interpretação errônea e aplicação divergente do conhecimento científico.

Assim, percebendo tal dificuldade em sua abordagem, os usos de métodos diferenciados no ensino de ciências podem vir a colaborar significativamente em sua compreensão, de forma a (re)construir novas perspectivas aos sujeitos e consequentemente, novas mudanças de suas posturas com relação ao ambiente. Para tanto, buscamos como problemática desta pesquisa: como os estudantes do compreendem os conceitos de preservação e conservação ambiental?

A pesquisa está fundamentada nos aportes da Teoria da aprendizagem significativa de David Paul Ausubel (AUSUBEL et al., 1980) e no Círculo Hermenêutico-Dialético de Guba e Lincoln (GUBA e LINCOLN, 1989), cuja relação nos possibilita buscar novos vislumbramento sobre esses conceitos e colaborar com o processo de ensino-aprendizagem para o Ensino de Ciências.

\section{OBJETIVO}

A pesquisa objetivou analisar as concepções estudantes do Ensino Médio sobre os conceitos de preservação e conservação ambiental, a parti da relação entre o conhecimento prévio e o círculo hermenêutico-dialético.

\section{A EDUCAÇÃO AMBIENTAL: REVISÃO DOS CONCEITOS DE PRESERVAÇÃO E CONSERVAÇÃO AMBIENTAL}

A Educação Ambiental (EA) evoca as discussões sobre o Meio Ambiente focando na interação entre a natureza e o homem, e não representa apenas a fauna e a flora, mas compreende os fatores abióticos, bióticos e a cultura humana e ainda é o fruto do trabalho dos seres humanos na sua relação com o ambiente (DIAS, 2002).

No que concerne aos conceitos de Preservação e Conservação Ambiental, o primeiro estaria relacionado à proteção da natureza, sem considerar a questão econômica ou de uso, visando a proteger o meio ambiente das ações do homem, mantendo assim, a natureza intocável. Já o segundo, trata do Meio Ambiente com a intenção de proteger, mas também de conviver e de usá-lo racionalmente, no uso apropriado, dentro dos limites capazes de manter sua qualidade e o equilíbrio em níveis satisfatórios, 'conservar' implica manejar, cuidar, manter, usar de forma racional (RIBEIRO, 2005).

Nesse sentido, apesar dos conceitos acima muitas vezes serem aplicados como sinônimos, ambos são distintos, mas que acabam por se apresentam como análogos, pois envolvem o cuidar do Meio Ambiente visando o equilíbrio dos ecossistemas, a manutenção da fauna e da flora e manutenção da vida humana na Terra. Assim, por envolverem conceitos relacionados com o ambiente, essa proximidade acaba por vezes, confundindo os estudantes em que muito trazem consigo conhecimentos prévios ou do senso comum, e que muitas vezes, apresentam-se engessados e que precisam ser reconstruídos numa visão cientifica.

Dessa forma, visando essa relação é necessário que as escolas explorem elementos sociais e políticos buscando oportunizando os sujeitos a refletirem sobre suas ações e proporem alternativas que visem mudanças significativas ao ambiente e a sociedade como um todo.

\section{TEORIA DA APRENDIZAGEM SIGNIFICATIVA: A IMPORTÂNCIA DOS CONHECIMENTOS PRÉVIOS NA (RE) CONSTRUÇÃO DE CONCEITOS}

Para David Paul Ausubel o conhecimento se dá pela construção ativa do sujeito da aprendizagem. A essência da teoria Ausubeliana é que "o fator isolado mais importante que influencia a aprendizagem é aquilo que o aluno já sabe” (MOREIRA, 1999, p. 152), ou seja, o ensino-aprendizagem deve se desenvolver a partir da identificação dos conhecimentos prévios dos estudantes, considerando-os como condição para que ocorra aprendizagem. 
Nessa perspectiva, as proposições de Ausubel et al. (1980) pressupõem que os indivíduos apresentam uma organização cognitiva interna baseada em conhecimentos de caráter conceitual, sendo que a sua complexidade depende muito mais das relações que esses conceitos estabelecem entre si, do número de conceitos presentes (MORAES, 2000).

Ausubel et al. (1980) afirmam que por meio de um material introdutório apresentando antes de trabalhar os conteúdos em sala de aula (organizadores prévios) possibilita a revisão dos conceitos, buscando na estrutura cognitiva dos alunos, ancorá-los e assim, reconstruir uma nova perspectiva conceitual (MOREIRA, 1997).

Assim, a aprendizagem consiste na "ampliação" da estrutura cognitiva, através da incorporação de novas ideias (AUSUBEL et al., 1980). E, dependendo do tipo de relacionamento que se tem entre as ideias já existentes nesta estrutura, e as novas que se estão internalizando pode ocorrer à aprendizagem significativa (MOREIRA, 1999), cujo aprendiz usa o novo conceito de forma inédita, independentemente do contexto em que este conteúdo foi primeiramente aprendido.

\section{O CÍRCULO HERMENÊUTICO-DIALÉTICO: UM MÉTODO DE REFLEXÃO CONCEITUAL}

O Círculo Hermenêutico-Dialético (CHD) foi instituído por Guba e Lincoln (1989), apresentado como um método qualitativo para coleta de dados. Essa técnica possui um caráter interativo, que une a hermenêutica através da mediação, do acordo e da unidade de sentido e a dialética por meio do diálogo, da crítica, da análise, das construções e das reconstruções coletivas, chegando num consenso, o mais próximo da realidade, permitindo ainda uma maior aproximação entre o pesquisador e os pesquisados (NEVES, 2006, NEVES et al., 2012).

A sua dinâmica se baseia em entrevistar todos os alunos pesquisados em sequência. Primeiramente, coletam-se as construções teóricas individuais do primeiro aluno e que serão apresentadas ao segundo aluno, que após a coleta de suas construções teóricas individuais terá a oportunidade de alterar ou não suas construções em função das colocações do entrevistado anterior e segue-se a repetir até o último entrevistado (NEVES, 2006; NEVES et al., 2012), conforme a Figura 1.

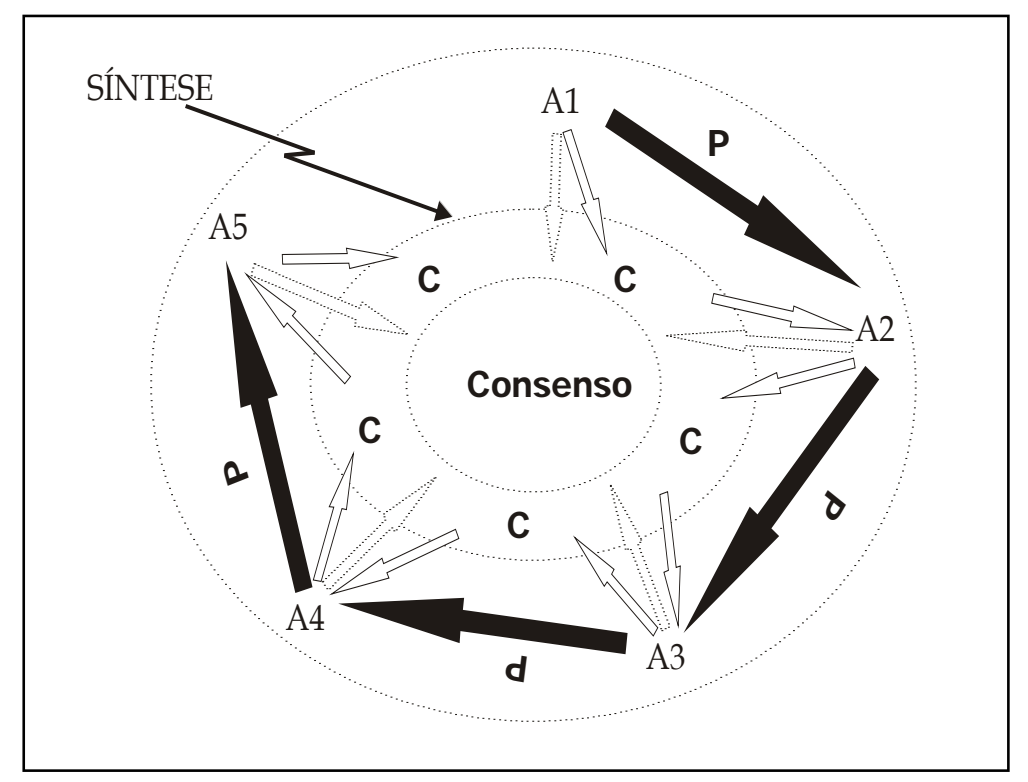

Figura 1. Esquema que ilustra o processo interativo da metodologia hermenêutica-dialética, onde A significa aluno entrevistado, C - significa construção teórica, e P - significa pesquisador. Fonte: Neves (2006, p. 56). 
A figura acima representa no primeiro círculo pontilhado o grupo de alunos entrevistados, enquanto que o segundo simboliza a dinâmica do "vai-e-vem" das construções e reconstruções teóricas e o terceiro a etapa que os alunos têm oportunidade de expor seus comentários conjuntamente e construir a concepção que representa o consenso do grupo sobre o assunto em questão. Assim, através da técnica do CHD é possível verificar com profundidade as reflexões iniciais, finais e grupais das reflexões apresentadas (NEVES 2006; NEVES et al., 2012).

\section{METODOLOGIA}

Esta pesquisa foi realizada com 30 alunos do terceiro ano do Ensino Médio em Vitória de Santo Antão, Pernambuco. O grupo pesquisado fazia parte do estágio obrigatório dos pesquisadores, o que oportunizou a realização das atividades nessa série.

Para a coleta das informações sobre os conceitos de preservação e conservação ambiental, que devido à complexidade envolvida na aplicação do CHD optamos por apresentar ao momento, apenas a etapa de consenso (construção do grupo) num quantitativo de cinco alunos.

Assim, a pesquisa seguiu o seguinte percurso metodológico:

- 1 - Aplicação do CHD para coleta de informações sobre as concepções prévias sobre os conceitos de preservação e conservação ambiental.

Para esse primeiro momento, utilizamos a proposta sugerida por Ausubel, quando dos conhecimentos prévios dos alunos. Então, os estudantes individualmente foram arguidos para que respondessem: 'O que você compreende por Preservação e Conservação Ambiental? Posteriormente, cada aluno de forma aleatória, formou um grupo de cinco pessoas, cujo objetivo foi de permitir que cada indivíduo lesse para os outros a sua ideia e em conjunto, procurassem reestruturá-la, de forma a constituir um consenso único sobre a pergunta em análise. Assim, formaria o segundo momento que envolvia etapa com o Círculo Hermenêutico-Dialético (CHD) e consideramos apenas o consenso do grupo.

- 2- Aula expositiva dialogada sobre:

- Importância do Meio Ambiente

- Conceitos de Preservação e Conservação;

- Analogias e problemas a respeito do tema;

- Comparações entre os conceitos.

Para compor esse momento, após aplicar o CHD, o professor iniciou a aula valorizando os conhecimentos prévios dos alunos, debatendo sobre a natureza, relacionando com um breve histórico sobre preservação e conservação, valorizando os conceitos não só com relação aos ecossistemas e das interações dos mesmos com o meio ambiente. Também alguns malefícios causados por ações antrópicas e possíveis iniciativas para minimizar os impactos, com analogias a respeito dos temas.

\section{- 3- Reaplicação do CHD}

Ao termino da aula foi novamente aplicado o CHD para observamos as mudanças nas concepções dos estudantes sobre os conceitos em estudo.

Para tanto, explicitamos a seguir, as construções teóricas iniciais e finais dos consensos do grupo (antes e após a intervenção). 


\section{RESULTADOS E DISCUSSÃO}

Inicialmente, foram analisados os consensos do grupo (cinco alunos) através do CHD, verificar as concepções prévias dos mesmos sobre o assunto a ser trabalhado, em seguida aplicado à aula e por fim novamente o CHD para comparar se houve ou não aprendizagem por parte dos alunos, conforme o Quadro 1, a seguir:

Quadro 1. Construções coletivas (consenso) dos alunos, sobre os conceitos de conservação e preservação.

\begin{tabular}{|c|c|c|}
\hline \multirow[b]{2}{*}{ Conceitos } & \multicolumn{2}{|r|}{ CONSENSO } \\
\hline & \begin{tabular}{|l|l} 
Concepção do grupo (Inicial) \\
\end{tabular} & Concepção do grupo (Final) \\
\hline Preservação & $\begin{array}{l}\text { "Preservar a natureza é você não } \\
\text { derrubar as árvores, combater o } \\
\text { desmatamento. E uma medida } \\
\text { viável para combater esses fatos } \\
\text { seria plantar mudas de árvores para } \\
\text { repor as que forem derrubadas”. }\end{array}$ & $\begin{array}{l}\text { “Deixar a natureza da forma que ela está não } \\
\text { tocar nela, nem extrair nada. Na preservação a } \\
\text { natureza tem que estar da forma em que foi } \\
\text { encontrada. Porém o que ocorre nos dias atuais } \\
\text { é que o ser humano não pratica proteger o meio } \\
\text { ambiente, com isso o consumo e a exploração se } \\
\text { tornam constante”. }\end{array}$ \\
\hline Conservação & $\begin{array}{l}\text { "Conservar a natureza é você tirar } \\
\text { dela tudo o que precisa, em } \\
\text { pequena quantidade e com } \\
\text { consumo responsável”. }\end{array}$ & $\begin{array}{l}\text { “A prática de conservação da natureza é bem } \\
\text { ampla, e começa pelo consumo consciente e } \\
\text { responsável, tirando dela só o necessário e } \\
\text { sempre repondo de volta, porque se não } \\
\text { devolvermos a ela o que tiramos um dia ela vai } \\
\text { acabar”. }\end{array}$ \\
\hline
\end{tabular}

Em linhas gerais, ao consenso inicial do grupo, a partir do conhecimento prévio de todos os estudantes foi possível notar que os conceitos de preservação e conservação ambiental enfocam apenas os ecossistemas terrestres, não havendo os ecossistemas aquáticos. Isso demonstra certa fragilidade na compreensão desses conceitos, vez que Dias (2002, p.32) afirma que o ambiente não é apenas fauna e flora, mas é formado pelos fatores abióticos e bióticos.

No consenso inicial com relação à preservação houve equívocos com relação a “combater o desmatamento", "plantar mudas de árvores para repor as que forem derrubadas”. Essa ideia estaria mais relacionada a conservação, visto que a preservação corresponde ao isolamento de uma espécie, sem que haja alguma intervenção antrópica.

No que concerne ao conceito de conservação, os estudantes consideraram apenas a ideia de consumismo, ou seja, retirar da natureza com responsabilidade, contudo deve haver um retorno mediante uma "restauração" do que foi retirado do ambiente.

Sobre a construção teórica final após a intervenção, o grupo pontuou que a preservação está relacionada a restringir a natureza das atividades humanas, ou seja, isolar a mesma. Quanto à conservação, o grupo exaltou que se deve utilizar da natureza com moderação, repondo o que foi tirado para que não haja um desgaste do ambiente.

\section{CONCLUSÕES}

Os conceitos de Preservação e de Conservação são assuntos pouco abordados no Ensino Médio, mas que precisam de maiores discussões, visando oportunizar aos estudantes uma ressignificação conceitual. Inicialmente, os alunos apresentavam dificuldades para distinguir os conceitos, que após o processo de intervenção houve significativa revisão das ideias pelo grupo, com considerações mais elaboradas e próximas do conhecimento científico.

A proposta de Ausubel por meio do conhecimento prévio permitiu compreendermos a importância a cerca das concepções individuais de cada individuo como algo fundamental para a formação do conhecimento científico. E, nessa perspectiva, as concepções individuais de cada 
um promoveram uma inteiração coletiva, pois partiu de suas próprias experiências, que culminaram numa relação social e por fim, na construção de novas ideias a cerca do conceito estudado.

A utilização do círculo hermenêutico-dialético (CHD) como ferramenta para a coleta de dados, por seu caráter dinâmico e interativo permitiu aos estudantes possibilidade de revisar as suas ideias e reconstruí-las com maior proximidade do conhecimento cientifico.

A valorização dos conhecimentos prévios elencados ao CHD foi de extrema importância para o processo de ensino-aprendizagem, cuja sinergia proporcionou novas perspectivas aos estudantes em relação aos conceitos e sobre o ambiente.

\section{REFERÊNCIAS}

AUSUBEL, D. P.; NOVAK, J. D.; HANESIA, H. Psicologia educacional. Rio de Janeiro: Interamericana, 1980.

BRASIL. Secretaria de Educação Fundamental. Parâmetros Curriculares Nacionais: Ciências da Natureza, Matemática e suas Tecnologias. Brasília: MEC/SEF, 2000.

DIAS, G. F. Iniciação a temática ambiental. São Paulo: Gaia, 2002.

FREITAS, S. H. A.; MATOS, V. D.; COSTA, H. N. O. Água, Sustentabilidade e Meio Ambiente: importância, problemas, conceitos, determinações e valorização - uma simples reflexão, Fortaleza, p.1-17, dez. 2015.

GUBA, E.; LINCOLN, Y. S. Fourth generation evaluation. Newbury Park: Sage, 1989.

MORAES, R. É possível ser construtivista no ensino de Ciências? Porto Alegre: EDIPURS, p. 103-158, 2000.

MOREIRA, M. A. Teorias de Aprendizagem. São Paulo: EPU, 1999.

NEVES, R. F. A interação do Ciclo da Experiência de Kelly com o Círculo HermenêuticoDialético para a Construção de Conceitos de Biologia. Recife: Universidade Federal Rural de Pernambuco, 2006. (Dissertação de mestrado).

NEVES, R. F.; CARNEIRO-LEÃO, A. M. A.; FERREIRA, H. S. A interação do ciclo da experiência de Kelly com o círculo hermenêutico-dialético, para a construção de conceitos de biologia. Ciênc. educ., v. 18, n. 2, p. 335-352, 2012.

RIBEIRO, I. J. L. Educação ambiental e representações sociais: uma análise transdisciplinar. Recife: Universidade Federal Rural de Pernambuco, 2005. (Dissertação de mestrado). 